Pacific Journal of Mathematics

RESTRICTED BIPARTITE PARTITIONS

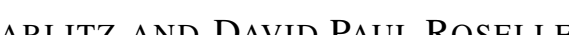




\title{
RESTRICTED BIPARTITE PARTITIONS
}

\author{
L. Carlitz and D. P. Roselle
}

Let $\pi_{k}(n, m)$ denote the number of partitions

$$
\begin{aligned}
& n=n_{1}+n_{2}+\cdots+n_{k} \\
& m=m_{1}+m_{2}+\cdots+m_{k}
\end{aligned}
$$

subject to the conditions

$$
\min \left(n_{j}, m_{j}\right) \geqq \max \left(n_{j+1}, m_{j+1}\right) \quad(j=1,2, \cdots, k-1) .
$$

Put

$$
\xi^{(k)}(x, y)=\sum_{n, m=0}^{\infty} \pi_{k}(n, m) x^{n} y^{m}
$$

We show that

$$
\begin{aligned}
& \xi^{(k)}(x, y)=\prod_{j=1}^{k} \frac{1-x^{2 j-1} y^{2 j-1}}{\left(1-x^{j} y^{j}\right)\left(1-x^{j} y^{j-1}\right)\left(1-x^{j-1} y^{j}\right)}, \\
& \sum_{n, m=0}^{\infty} \pi(n, m ; \lambda) x^{n} y^{m}=1+(1-\lambda) \sum_{k=1}^{\infty} \lambda^{k} \xi^{(k)}(x, y), \\
& \sum_{n=0}^{\infty} \phi(n, m) x^{n} y^{m}=\sum_{n=0}^{\infty} x^{n} y^{n} \xi^{(n)}\left(x^{2}, y^{2}\right),
\end{aligned}
$$

where $\pi(n, m ; \lambda)$ denotes the number of "weighted" partitions of $(n, m)$ and $\psi(n, m)$ is the number of partitions into odd parts $\left(n_{j}, m_{j}\right.$ all odd).

Consider partitions of the bipartite $(n, m)$ of the type

$$
\begin{aligned}
n & =n_{1}+n_{2}+n_{3}+\cdots \\
m & =m_{1}+m_{2}+m_{3}+\cdots,
\end{aligned}
$$

where the $n_{j}, m_{j}$ are nonnegative integers subject to the conditions

$$
\min \left(n_{j}, m_{j}\right) \geqq \max \left(n_{j+1}, m_{j+1}\right) \quad(j=1,2,3, \cdots) .
$$

For brevity we may write (1.2) in the form

$$
\left(n_{j}, m_{j}\right) \geqq\left(n_{j+1}, m_{j+1}\right) \quad(j=1,2,3, \cdots)
$$

and say that the "parts" of the partition (1.1) decrease.

Let $\pi(n, m)$ denote the number of partitions (1.1) that satisfy (1.2) and let $\rho(n, m)$ denote the numbers of partitions (1.1) that satisfy

$$
\left(n_{j}, m_{j}\right)>\left(n_{j+1}, m_{j+1}\right) \quad(j=1,2,3, \cdots) .
$$

By the inequality (1.3) is understood 


$$
\min \left(n_{j}, m_{j}\right)>\max \left(n_{j+1}, m_{j+1}\right) \quad(j=1,2,3, \cdots) .
$$

The generating functions for $\pi(n, m)$ and $\rho(n, m)$ are given by [2]

$$
\begin{gathered}
\prod_{j=1}^{\infty}\left(1-x^{2 j} y^{2 j}\right)^{-1}\left(1-x^{j} y^{j-1}\right)^{-1}\left(1-x^{j-1} y^{j}\right)^{-1}, \\
\frac{1-x y}{(1-x)(1-y)} \sum_{n=0}^{\infty}(x y)^{n(n+1) / 2} \prod_{j=1}^{n} \frac{1-x^{2 j+1} y^{2 j+1}}{\left(1-x^{j} y^{j}\right)\left(1-x^{j+1} y^{j}\right)\left(1-x^{j} y^{j+1}\right)},
\end{gathered}
$$

respectively.

For the case of unipartite (natural) numbers generating functions are known for partitions with parts restricted in various ways [3]. The notion of a part of the partition (1.1) implied by the conditions (1.2) suggests that these results can be extended to bipartite numbers. For example, we may think of $\rho(n, m)$ as the number of partitions of $(n, m)$ with unequal parts. We shall find generating functions for bipartite partitions with at most $k$ parts, weighted parts, and odd parts.

2. Partitions with at most $k$ parts. We consider partitions of the type

$$
\begin{aligned}
& n=n_{1}+n_{2}+\cdots+n_{k} \\
& m=m_{1}+m_{2}+\cdots+m_{k},
\end{aligned}
$$

where the $n_{j}, m_{j}$ are nonnegative integers subject to the conditions

$$
\left(n_{j}, m_{j}\right) \geqq\left(n_{j+1}, m_{j+1}\right) \quad(j=1,2, \cdots, k-1) .
$$

Let $\pi_{k}(n, m)$ denote the number of partitions (2.1) subject to the conditions (2.2) and let $\pi_{k}(n, m \mid a, b)$ denote the numbers of these partitions that also satisfy

$$
(a, b) \geqq\left(n_{1}, m_{1}\right) \text {. }
$$

Note that $\pi(n, m)$ defined in $\S 1$ satisfies

$$
\pi(n, m)=\lim _{k=\infty} \pi_{k}(n, m) .
$$

We define the rational function $\xi_{a b}^{(k)}$ of $x$ and $y$ by the recurrence

$$
\xi_{a b}^{(0)}=1, \quad \xi_{a b}^{(k)}=\sum_{r, s=0}^{\min (a, b)} x^{r} y^{s} \xi_{r s}^{(k-1)} \quad(k \geqq 1) .
$$

If we put

$$
\xi^{(k)}=\xi_{\infty \infty}^{(k)},
$$

then in the limit (2.5) becomes 


$$
\xi^{(k)}=\sum_{r=0}^{\infty} x^{r} y^{s} \xi_{r s}^{(k-1)} \quad(k \geqq 1) .
$$

It is clear from (2.5) that $\xi_{a b}^{(k)}$ is the generating function for $\pi_{k}(n, m \mid a, b)$. Thus it follows from (2.6) that $\xi^{(k)}$ is the generating function for $\pi_{k}(n, m)$. Explicitly, we have

$$
\begin{gathered}
\xi_{a b}^{(k)}=\sum_{n, m=0}^{\infty} \pi_{k}(n, m \mid a, b) x^{n} y^{m}, \\
\xi^{(k)}=\sum_{n, m=0}^{\infty} \pi_{k}(n, m) x^{n} y^{m} .
\end{gathered}
$$

We define the generating functions

$$
\begin{aligned}
F_{k}(u, v) & =\sum_{r, s=0}^{\infty} u^{r} v^{s} \xi_{r s}^{(k-1)}, \\
F_{k}^{(u)} & =\sum_{n=0}^{\infty} u^{n} \xi_{n n}^{(k-1)},
\end{aligned}
$$

so that

$$
F_{k}(x, y)=\xi^{(k)} .
$$

Using (2.10), (2.11) and

$$
\xi_{r r}^{(k)}=\xi_{a b}^{(k)} \quad(r=\min (a, b)),
$$

we get

$$
\begin{aligned}
F_{k}(u, v) & =\sum_{r \geqq s} u^{r} v^{s} \xi_{s s}^{(k-1)}+\sum_{s \geqq r} u^{r} v^{s} \xi_{r r}^{(k-1)}-\sum_{r=0}^{\infty} u^{r} v^{r} \xi_{r r}^{(k-1)} \\
& =\left(\frac{1}{1-u}+\frac{1}{1-v}-1\right) F_{k}(u v)
\end{aligned}
$$

It follows that

$$
F_{k}(u, v)=\frac{1-u v}{(1-u)(1-v)} F_{k}(u v)
$$

On the other hand, using (2.5), (2.11), and (2.13), we get

$$
\begin{aligned}
F_{k}(u) & =\sum_{n=0}^{\infty} u^{n} \sum_{r, s=0}^{n} x^{r} y^{s} \xi_{r s}^{(k-2)} \\
& =\frac{1}{1-u}\left(\sum_{r \geq s} u^{r} x^{r} y^{s} \xi_{s s}^{(k-1)}+\sum_{s \geq r} u^{s} y^{s} x^{r} \xi_{r r}^{(k-1)}-\sum_{r=0}^{\infty}(x y u)^{r} \xi_{r r}^{(k-1)}\right) \\
& =\frac{1}{1-u}\left(\frac{1}{1-u x}+\frac{1}{1-u y}-1\right) F_{k-1}(x y u),
\end{aligned}
$$

which implies 
(2.15) $\quad F_{k}(u)=\frac{1-x y u^{2}}{(1-u)(1-x u)(1-y u)} F_{k-1}(x y u) \quad(k \geqq 1)$.

It follows from (2.5), (2.11), and (2.15) that

(2.16) $\quad F_{k}(u)=\frac{1}{1-u} \prod_{\jmath=0}^{k-2} \frac{1-x^{2 j+1} y^{2 j+1} u^{2}}{\left(1-x^{j+1} y^{j+1} u\right)\left(1-x^{j} y^{j+1} u\right)\left(1-x^{j+1} y^{j} u\right)}$.

Thus, using (2.12) and (2.14), we have evidently proved

TheOREm 1. If $\xi^{(k)}$ is defined by (2.9) then

$$
\xi^{(k)}=\prod_{j=1}^{k} \frac{1-x^{2 j-1} y^{2 j-1}}{\left(1-x^{j} y^{j}\right)\left(1-x^{j} y^{j-1}\right)\left(1-x^{j-1} y^{j}\right)} .
$$

We may now write (1.5) in the form

$$
\sum_{n=1}^{\infty}(x y)^{n(n-1) / 2}\left(1-x^{n} y^{n}\right) \xi^{(n)}(x, y),
$$

which is analogous to the well-known identity

$$
\prod_{n=1}^{\infty}\left(1+x^{n}\right)=\sum_{n=1}^{\infty} x^{n(n-1) / 2} \prod_{j=1}^{n-1}\left(1-x^{j}\right)^{-1} .
$$

3. A q-identity. If we put

$$
\xi=\xi^{(\infty)}, \quad \xi_{a b}=\xi_{a b}^{(\infty)},
$$

then it follows from (2.4) and (2.9) that $\xi$ is the generating function for $\pi(n, m)$. Moreover, it is clear from (2.14) and (2.16) that

$$
\begin{aligned}
F(u, v) & =\sum_{r, s=0}^{\infty} u^{r} v^{s} \xi_{r s}=\frac{1-u v}{(1-u)(1-v)} F(u v), \\
F(u) & =\sum_{n=0}^{\infty} u^{n} \xi_{n n} \\
& =e(u, x y) e(x u, x y) e(y u, x y) \prod_{j=0}^{\infty}\left(1-x^{2 j+1} y^{2 j+1} u^{2}\right),
\end{aligned}
$$

where

$$
\begin{aligned}
& e(t)=e(t, q)=\prod_{0}^{\infty}\left(1-q^{n} t\right)^{-1}=\prod_{0}^{\infty} \frac{t^{n}}{(q)_{n}}, \\
& (q)_{n}=(1-q)\left(1-q^{2}\right) \cdots\left(1-q^{n}\right) .
\end{aligned}
$$

We define the polynomial

$$
H_{n}(x)=H_{n}(x, q)=\sum_{r=0}^{n}\left[\begin{array}{l}
n \\
r
\end{array}\right] x^{r},
$$


where

$$
\left[\begin{array}{l}
n \\
r
\end{array}\right]=\frac{(q)_{n}}{(q)_{r}(q)_{n-r}}
$$

It has been shown [1] that

$$
\sum_{0}^{\infty} \frac{H_{k}(x) H_{k}(y)}{(q)_{k}} t^{k}=\frac{e(t) e(x t) e(y t) e(x y t)}{e\left(x y t^{2}\right)} .
$$

Using (3.3), (3.4), and (3.6), we then have

$$
\sum_{0}^{\infty} u^{n} \xi_{n n}=\sum_{0}^{\infty} \frac{H_{k}(x) H_{k}(y)}{(x y)_{k}} u^{k} \sum_{0}^{\infty}(-1)^{r} \frac{x^{r} y^{r} u^{r}}{(x y)_{r}} .
$$

Comparing coefficients of $u^{n}$, we get

$$
\xi_{n n}=\frac{1}{(x y)_{n}} \sum_{k=0}^{n}(-1)^{n-k}\left[\begin{array}{l}
n \\
k
\end{array}\right] x^{n-k} y^{n-k} H_{k}(x) H_{k}(y) .
$$

Note that $x y=q$ in the right member of (3.7).

It is clear from (3.7) that

$$
P_{n}(x, y)=(x y)_{n} \xi_{n n}
$$

is a polynomial in $x, y$ with integral coefficients which satisfies

$$
\begin{aligned}
& P_{n}(x, y)=P_{n}(y, x), \\
& P_{n}(x, 0)=\frac{1-x^{n+1}}{1-x}, \\
& x^{n} P_{n}\left(x, \frac{1}{x}\right)=\left(x^{2}+x+1\right)^{n} .
\end{aligned}
$$

Also it follows from $(2.15)$ that $P_{n}(x, y)$ satisfies the recurrence

$$
\begin{aligned}
& P_{n}-(1+x+y) P_{n-1}+[n-1]\left(x+y+x y+x^{n-1} y^{n-1}\right) P_{n-2} \\
& \quad-x y[n-1][n-2] P_{n-3}=0,
\end{aligned}
$$

where $[j]=1-x^{j} y^{j}$.

4. Weighted partitions. We define $\pi(n, m ; \lambda)$, the number of weighted partitions of the bipartite $(n, m)$, by the relation

$$
\pi(n, m ; \lambda)=\sum_{k=0}^{\infty} \lambda^{k} \sum 1,
$$

where the inner sum is extended over all partitions of the form (2.1) subject to the conditions (2.2) and the additional condition $\max \left(n_{k}, m_{k}\right)>$ 0 ; that is, over all partitions with exactly $k$ parts. It follows from the definition of $\pi_{k}(n, m)$ that we may write $(4.1)$ in the form 


$$
\pi(n, m ; \lambda)=\sum_{k=0}^{\infty} \lambda^{k}\left(\pi_{k}(n, m)-\pi_{k-1}(n, m)\right) .
$$

It should be remarked that the sum in (4.2) is finite, the upper bound for $k$ being $\max (n, m)$.

Multiplying both members of (4.2) by $x^{n} y^{m}$ and summing over $n$, $m$ it follows from (2.9) and (2.17) that we have established

\section{THEOREM 2. We have}

$$
\sum_{n, m=0}^{\infty} \pi(n, m ; \lambda) x^{n} y^{m}=1+(1-\lambda) \sum_{k=1}^{\infty} \lambda^{k} \xi^{(k)}(x, y) .
$$

Note that (4.3) is a direct analogue of the well-known identity

$$
\prod_{n=1}^{\infty}\left(1-\lambda x^{n}\right)^{-1}=\sum_{n=0}^{\infty} \lambda^{n} x^{n} \sum_{j=1}^{n}\left(1-x^{j}\right)^{-1} .
$$

We remark that (4.3) may be proved in a different manner. If we put

$$
\xi_{a b}(\lambda)=1+\lambda \sum_{r, s=0}^{\min (a, b)} x^{r} y^{s} \xi_{r s},
$$

where the prime denotes that we sum over all $r, s$ in the indicated range except $r=s=0$, then it follows from (4.1) that

$$
\xi(\lambda)=\xi_{\infty \infty}(\lambda)
$$

is the generating function for $\pi(n, m ; \lambda)$. We may then evaluate $\xi(\lambda)$ by the methods of $\S 2$.

5. Partitions into odd parts. We shall say that the $j$-th part of the partition (1.1) is odd if each of $n_{j}, m_{j}$ is odd.

Let $\psi(n, m)$ denote the number of partitions of the form (1.1) with parts odd and subject to the conditions (1.2). Let $\psi(n, m \mid a, b)$ denote the number of these partitions that satisfy the additional condition

$$
(2 a+1,2 b+1) \geqq\left(n_{1}, m_{1}\right) .
$$

We define the rational function $\beta_{2 a+1,2 b+1}$ of $x, y$ by the relation

$$
\beta_{2 a+1,2 b+1}=1+\sum_{r, s=0}^{\min (a b)} x^{2 r+1} y^{2 s+1} \beta_{2 r+1,2 s+1},
$$

so that

$$
\beta_{2 r+1,2 r+1}=\beta_{2 a+1,2 b+1} \quad(r=\min (a, b)) .
$$

If we put 


$$
\beta=\beta_{\infty \infty},
$$

then in the limit (5.2) becomes

$$
\beta=1+\sum_{r, s=0}^{\infty} x^{2 r+1} y^{2 s+1} \beta_{2 r+1,2 s+1} .
$$

It follows from (5.2) that

$$
\beta_{2 a+1,2 b+1}=\sum_{n, m=0}^{\infty} \psi(n, m \mid a, b) x^{n} y^{m} .
$$

Thus, using (5.5), we get

$$
\beta=\sum_{n, m=0}^{\infty} \psi(n, m) x^{n} y^{m}
$$

We define the generating functions

$$
\begin{gathered}
H(u, v)=\sum_{r, s=0}^{\infty} u^{r} v^{s} \beta_{2 r+1,2 s+1}, \\
H(u)=\sum_{n=0}^{\infty} u^{n} \beta_{2 n+1,2 n+1},
\end{gathered}
$$

so that

$$
\beta=1+x y H\left(x^{2}, y^{2}\right) .
$$

Using (5.3), (5.8) and (5.9), we have

$$
H(u, v)=\frac{1-u v}{(1-u)(1-v)} H(u v) .
$$

The proof of (5.11) is exactly like that of (2.14).

On the other hand, it follows from (5.2), (5.3), and (5.9) that

$$
\begin{aligned}
H(u) & =\sum_{n=0}^{\infty} u^{n}\left(1+\sum_{r, s=0}^{n} x^{2 r+1} y^{2 s+1} \beta_{2 r+1,2 s+1}\right) \\
& =\frac{1}{1-u}+\frac{x y}{1-u} \sum_{r, s=0}^{\infty} x^{2 r} y^{2 s} u^{\max (r, s)} \beta_{2 r+1,2 s+1} \\
& =\frac{1}{1-u}+\frac{x y}{1-u}\left(\frac{1}{1-x^{2} u}+\frac{1}{1-y^{2} u}-1\right) H\left(x^{2} y^{2} u\right),
\end{aligned}
$$

which implies

$$
H(u)=\frac{1}{1-u}\left(1+\frac{1-x^{2} y^{2} u^{2}}{\left(1-x^{2} u\right)\left(1-y^{2} u\right)} H\left(x^{2} y^{2} u\right)\right) .
$$

Repeated applications of (5.12) yield 


$$
\begin{aligned}
& H(u)= \\
& \frac{1}{1-u} \sum_{n=0}^{\infty} x^{n} y^{n} \prod_{j=1}^{n} \frac{1-x^{4 j+2} y^{4 j+2} u^{2}}{\left(1-x^{2 j+2} y^{2 j+2} u\right)\left(1-x^{2 j} y^{2 j+2} u\right)\left(1-x^{2 j+2} y^{2 j} u\right)} .
\end{aligned}
$$

Thus, using (5.10), (5.11), and (2.17), we may state

THEOREM 3. If $\psi(n, m)$ denotes the number of partitions of $(n, m)$ with odd parts, then

$$
\sum_{n, m=0}^{\infty} \psi(n, m) x^{n} y^{m}=\sum_{n=0}^{\infty} x^{n} y^{n} \xi^{(n)}\left(x^{2}, y^{2}\right)
$$

where $\xi^{(n)}(x, y)$ is defined by (2.17).

The fact that (2.18) and (5.14) are analogous to well-known identities for unipartite numbers leads one to conjecture that $\rho(n, m)=$ $\psi(n, m)$. There are, however, counterexamples to this conjecture. For example, it is easily verified that

$$
\rho(5,4)=6 \neq 4=\psi(5,4) .
$$

It would be of interest to know whether generally

$$
\rho(n, m) \geqq \psi(n, m) \text {. }
$$

\section{REFERENCES}

1. L. Carlitz, Some polynomials related to theta functions, Annali di Mathematica 41 (1955), 359-73.

2. L. Carlitz, A problem in partitions, Duke Math. J. 30 (193), 202-13.

3. G. H. Hardy and E. M. Wright, The Theory of Numbers, 3rd edition, Oxford, 1954:

Received March 20, 1965.

DUKe University

AND

UNIVERSITY OF MARYLAND 


\title{
PACIFIC JOURNAL OF MATHEMATICS
}

\author{
EDITORS
}

\section{H. SAMELSON}

Stanford University

Stanford, California

J. P. JANS

University of Washington

Seattle, Washington 98105
J. DugundJI

University of Southern California

Los Angeles, California 90007

RICHARD ARENS

University of California

Los Angeles, California 90024

\section{ASSOCIATE EDITORS}

\section{E. F. BECKENBACH}

B. H. NEUMANN

F. WOLF

K. YosidA

\section{SUPPORTING INSTITUTIONS}

\author{
UNIVERSITY OF BRITISH COLUMBIA \\ CALIFORNIA INSTITUTE OF TECHNOLOGY \\ UNIVERSITY OF CALIFORNIA \\ MONTANA STATE UNIVERSITY \\ UNIVERSITY OF NEVADA \\ NEW MEXICO STATE UNIVERSITY \\ OREGON STATE UNIVERSITY \\ UNIVERSITY OF OREGON \\ OSAKA UNIVERSITY \\ UNIVERSITY OF SOUTHERN CALIFORNIA
}

\author{
STANFORD UNIVERSITY \\ UNIVERSITY OF TOKYO \\ UNIVERSITY OF UTAH \\ WASHINGTON STATE UNIVERSITY \\ UNIVERSITY OF WASHINGTON \\ AMERICAN MATHEMATICAL SOCIETY \\ CHEVRON RESEARCH CORPORATION \\ TRW SYSTEMS \\ NAVAL ORDNANCE TEST STATION
}

Mathematical papers intended for publication in the Pacific Journal of Mathematics should be typewritten (double spaced). The first paragraph or two must be capable of being used separately as a synopsis of the entire paper. It should not contain references to the bibliography. Manuscripts may be sent to any one of the four editors. All other communications to the editors should be addressed to the managing editor, Richard Arens at the University of California, Los Angeles, California 90024.

50 reprints per author of each article are furnished free of charge; additional copies may be obtained at cost in multiples of 50 .

The Pacific Journal of Mathematics is published monthly. Effective with Volume 16 the price per volume (3 numbers) is $\$ 8.00$; single issues, $\$ 3.00$. Special price for current issues to individual faculty members of supporting institutions and to individual members of the American Mathematical Society: $\$ 4.00$ per volume; single issues $\$ 1.50$. Back numbers are available.

Subscriptions, orders for back numbers, and changes of address should be sent to Pacific Journal of Mathematics, 103 Highland Boulevard, Berkeley 8, California.

Printed at Kokusai Bunken Insatsusha (International Academic Printing Co., Ltd.), No. 6, 2-chome, Fujimi-cho, Chiyoda-ku, Tokyo, Japan.

PUBLISHED BY PACIFIC JOURNAL OF MATHEMATICS, A NON-PROFIT CORPORATION

The Supporting Institutions listed above contribute to the cost of publication of this Journal, but they are not owners or publishers and have no responsibility for its content or policies. 


\section{Pacific Journal of Mathematics \\ Vol. 19, No. $2 \quad$ June, 1966}

Leonard Daniel Baumert, Extreme copositive quadratic forms . ......... 197

Fred James Bellar, Jr., Pointwise bounds for the second initial-boundary value problem of parabolic type ........................ 205

L. Carlitz and David Paul Roselle, Restricted bipartite partitions ........ 221

Robin Ward Chaney, On the transformation of integrals in measure space ........................................... 229

Colin W. Clark, An embedding theorem for function spaces ........... 243

Edwin Duda, A theorem on one-to-one mappings................ 253

Ben Fitzpatrick, Jr. and Donald Reginald Traylor, Two theorems on metrizability of Moore spaces.......................... 259

Allen Roy Freedman, An inequality for the density of the sum of sets of vectors in $n$-dimensional space ....................... 265

Michael Friedberg, On representations of certain semigroups .......... 269

Robert William Gilmer, Jr., The pseudo-radical of a commutative ring . . . . 275

Hikosaburo Komatsu, Fractional powers of operators ............... 285

Daniel Rider, Transformations of Fourier coefficients ................. 347

David Alan Sánchez, Some existence theorems in the calculus of variations ...................................... 357

Howard Joseph Wilcox, Pseudocompact groups............... 365

William P. Ziemer, Some lower bounds for Lebesgue area ............. 381 